\title{
The Need for Research in Broadening Participation
}

Tiffany Barnes

North Carolina State University

George K. Thiruvathukal

Loyola University Chicago, gkt@cs.luc.edu

Follow this and additional works at: https://ecommons.luc.edu/cs_facpubs

Part of the Computer Sciences Commons, and the Science and Mathematics Education Commons

\section{Recommended Citation}

Tiffany Barnes and George K. Thiruvathukal, The Need for Research in Broadening Participation, Communications of the ACM, Vol. 59 No. 3, Pages 33-34, 10.1145/2880177

This Article is brought to you for free and open access by the Faculty Publications and Other Works by Department at Loyola eCommons. It has been accepted for inclusion in Computer Science: Faculty Publications and Other Works by an authorized administrator of Loyola eCommons. For more information, please contact ecommons@luc.edu.

\section{(c) $\odot \ominus$}

This work is licensed under a Creative Commons Attribution-Noncommercial-No Derivative Works 3.0 License. 


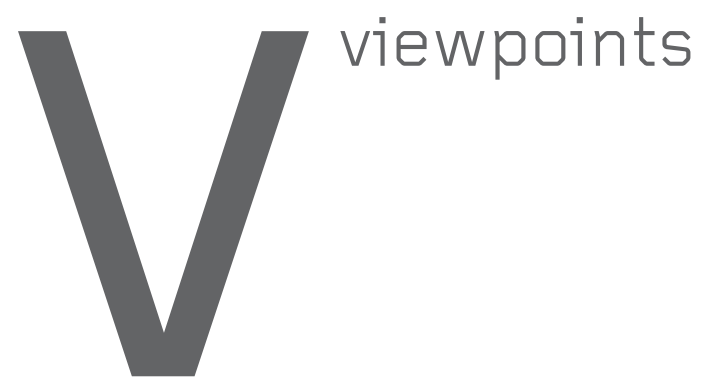

Broadening Participation The Need for Research in Broadening Participation

In addition to alliances created for broadening participation in computing, research is required to better utilize the knowledge they have produced.

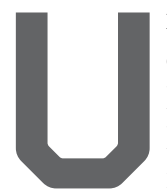

NDERREPRESENTATION IN COMPUTING is a global problem, marked by a disturbing lack of access to computing resources and education among people underrepresented by race, ethnicity, gender, income, disability, and sexual-orientation status. It is urgent that we address this divide between those with and without the knowledge to create computational artifacts or even basic functional literacy. Important alliances for broadening participation (BP) are catalyzing efforts to engage more people in computing, but they are not enough. We need solid research as well.

The U.S. National Science Foundation (NSF) has funded eight current Broadening Participation in Computing Alliances to increase the diversity of computing students in the U.S. These alliances have built networks among diverse computing students and professionals while building capacity to improve the culture of computing. The National Center for Women \& Information Technology (NCWIT; https://www. ncwit.org/) has mobilized over 600 organizations to recruit, retain, and advance women in computing. The Computing Alliance for Hispanic-Serving Institutions (CAHSI; http://cahsi.cs.utep.edu/) has provided mentoring and effective educational practices like peer-led team learning and the Affinity Research Group model to integrate undergraduates into research teams. The Alliance for Access to Computing Careers (Ac-

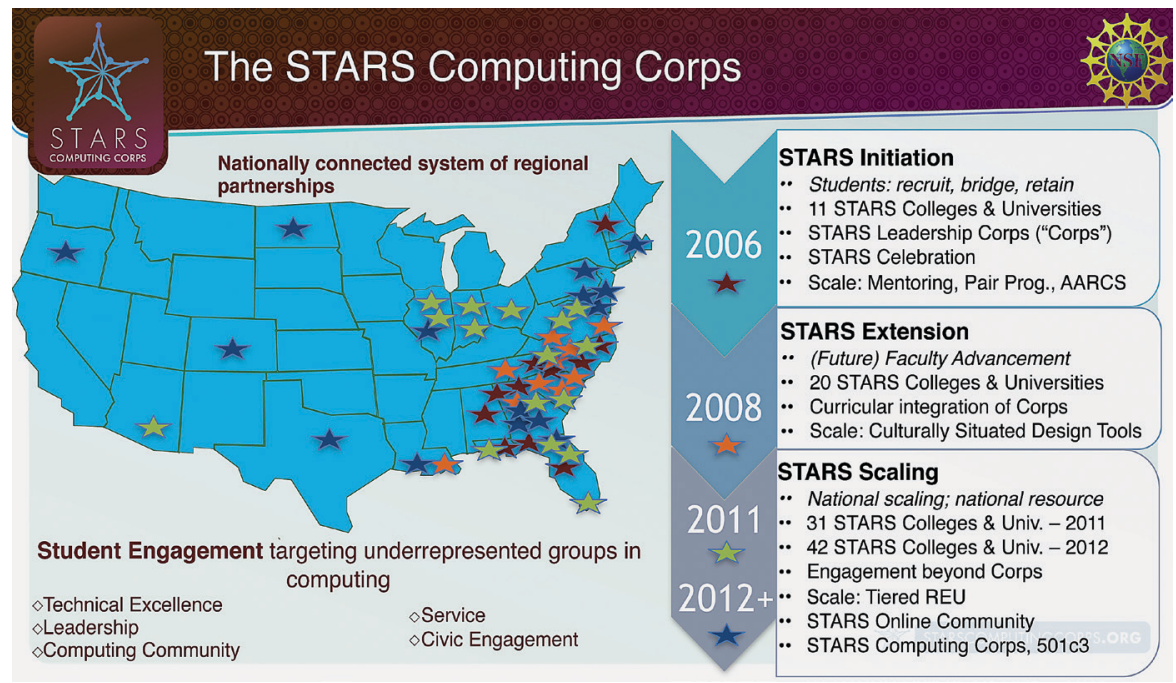

The STARS Computing Corps is one of eight NSF-funded Broadening Participation in Computing Alliances.

cessComputing; http://www.washington.edu/accesscomputing/) promotes inclusive practices and builds community for students with disabilities. The Institute for African American Mentoring in Computer Sciences (IAAMCS; http://www.iaamcs.org/) encourages undergraduate students in research, $\mathrm{K}-12$ outreach, and participation in seminars and the Tapia Celebration of Diversity in Computing (http://tapiaconference.org/). Expanding Computing Education Pathways (ECEP; http:// expandingcomputing.cs.umass.edu/) supports state-level computing education reforms. Into the Loop (http:// exploringes.org/) works to integrate rigorous computing courses in Los Angeles Unified School District high schools. The Computing Research Association-Women (CRA-W; http://cra. org/cra-w) and the Coalition to Diversity Computing (CDC; http://www.cdccomputing.org/) support Sustainable Diversity in the Computing Research Pipeline (http://cra.org/cerp/), and the Data Buddies project across programs. The STARS Computing Corps (http:// starscomputingcorps.org) develops university and student leaders to serve local communities through regional partnerships and an annual STARS Celebration conference.

\section{BP Research Needs}

Alliances build support for underrepresented groups through extensive, interdisciplinary research at the boundaries 
of computing, education, and the social sciences, but such work is underestimated and undervalued, with few publication venues and low disciplinary recognition. ${ }^{3}$ To leverage the knowledge alliances are building, research is needed to identify what works, to replicate it, and to synthesize findings into a theoretical framework. Computing professionals and researchers must value this BP research, credit those doing this difficult work, and help them advance their careers. This can only happen with the support of a dedicated community that produces peer-reviewed conferences and journals. ${ }^{4}$ The STARS Computing Corps (http://starscomputingcorps.org) has helped foster this new professional community.

Since its founding in 2006, STARS has mobilized more than 80 faculty and 2,100 students at 51 colleges and universities to lead projects that broaden participation in computing. STARS has focused on BP interventions, such as student-led outreach projects that have reached over 130,000 K-12 students. At the annual STARS Celebration conference, STARS students and faculty share their work and meet with BP thought leaders. Support, recognition, and a peer-review process were enlisted from professional societies to expand the Celebration conference to include a new conference on BP research. ${ }^{4}$ The IEEE Computer Society Special Technical Community (STC) on Broadening Participation helped sponsor RESPECT'15, (Research on Equity and Sustained Participation in Engineering, Computing, and Technology, held August 13-14, 2015 in Charlotte, NC; http://respect2015.stcbp.org/). The IEEE Computer Society's STCBP and the ACM Special Interest Group on Computer Science Education (SIGCSE; http://www.sigcse.org/), have helped establish a community that ensures rigorous BP research publications. These publications are available to IEEE and ACM members through the organizations' digital libraries.

\section{Research and the RESPECT Conference}

The RESPECT interdisciplinary research conference draws on computer science, education, learning sciences, and the social sciences. It builds the foundation for broadening participa-

\section{We, as computing professionals, have a responsibility to improve computing culture to be more inclusive for everyone.}

tion research. The first annual STCBP conference, RESPECT'15, was co-organized by STARS and co-located with the STARS Celebration (http://www. starscomputingcorps.org) to leverage and engage the existing activist-oriented STARS community in BP research. The RESPECT and Celebration conferences' joint "RESPECT for Diversity" theme highlighted our common belief that the engagement of diverse people in computing is a matter of equity - all people deserve the opportunity to engage in work that is integral to solving increasingly complex global challenges.

RESPECT'15 research papers showed BP programs are effective, and are more impactful for people from underrepresented groups. Many of these programs engage people from underrepresented groups in BP work-but this could, ironically, limit the diverse perspectives that impact technical innovations. Exploding demand for computing degrees is outpacing growth in computing programs-disproportionately impacting those without access to the "preparatory privilege" of extra experience in science, technology, engineering, math, and computer science. ${ }^{5}$ Zweben and Bizot ${ }^{7}$ found that the percentage of women in undergraduate programs in computing is continuing to decline. Robinson et al. ${ }^{6}$ studied diverse students, finding that subtle racial and gendered discriminations called microaggressions erode the culture and student experience in graduate engineering programs.

We, as computing professionals, have a responsibility to improve computing culture to be more inclusive for everyone. Educators should consider how to enable students to become more interested in and excited about computing. Professionals should reach out and help others learn computing by connecting through STARS, NCWIT, or other alliances. Parents can encourage their children to learn computing, and lobby schools to get computing in the curriculum. Leaders should consider how to change company culture and practices to create more diverse technical and leadership teams. These actions should be informed by emerging BP research, such as the RESPECT'15 proceedings. ${ }^{1}$ and the Computing in Science \& Engineering special issue on the best of RESPECT. ${ }^{2}$ Those committed to broadening participation are welcome to join the IEEE Computer Society's special technical community on Broadening Participation (http://stcbp. org) and to participate in RESPECT'16 and the STARS Celebration in Atlanta, GA, from August 11-13, 2016.

\section{References}

1. Barnes, T. et al. In Proceedings of the First Annual International Conference on Research on Equity and Sustained Participation in Engineering, Computing, and Technology (RESPECT'15), Charlotte, NC, (Aug. 13-14, 2015); http://bit.ly/1JplqRe.

2. Barnes, T. et al. Special issue on the best of RESPECT 2015. Computing in Science and Engineering (2016); http://bit.ly/1nDIS3l.

3. Chubin, D.E. and Johnson, R.Y. A program greater than the sum of its parts: The BPC alliances. Commun. ACM 54, 3 (Mar. 2011), 35-37; DOI: http://dx.doi. org/10.1145/1897852.1897866

4. Dahlberg, T. Why we need an ACM special interest group for broadening participation. Commun. ACM 55 12 (Dec. 2012), 36-38.

5. Margolis, J. et al. Stuck in the Shallow End: Education Race, and Computing. MIT Press, 2008.

6. Robinson, W.H. et al. Racial and gendered experiences that dissuade a career in the professoriate. Research in Equity and Sustained Participation in Engineering. Computing, and Technology (RESPECT) (Aug. 2015), 1-5.

7. Zweben, S.H. and Bizot, B. Representation of women in postsecondary computing 1990-2013: Disciplines, institutional, and individual characteristics matter. In Research in Equity and Sustained Participation in Engineering, Computing, and Technology (RESPECT 2015). IEEE, 2015, 1-8.

Tiffany Barnes (tiffany.barnes@gmail.com) is an associate professor of Computer Science at North Carolina State University, Raleigh, NC. She co-chairs the IEEE Computer Special Technical Community on Broadening Participation and serves on executive boards for ACM SIGCSE, EDM, and AIED.

George K. Thiruvathukal (gkt@cs.luc.edu) is Professor of Computer Science at Loyola University Chicago and a Visiting Computer Scientist at Argonne National Laboratory in the Mathematics and Computer Science Division/Argonne Leadership Computing Facility. He co-chairs the Special Technical Community on Broadening Participation.

RESPECT'15 was made possible by NSF funding (CNS1042372), the STARS Computing Corps, technical cosponsorship by IEEE Computer Society, and in-cooperation status with ACM SIGCSE. We particularly thank RESPECT local chair and STARS PI Jamie Payton, and RESPECT program chairs Kristy Boyer and Jeff Forbes. The authors thank Jenny Stout, editor of Computing in Science and Engineering, and NC State Ph.D. students Thomas Price and Drew Hicks for comments on drafts of this column

Copyright held by authors. 